\title{
Application Status and Evaluation of Aquatic Plants in Wuhan Landscape Waters
}

\author{
Shijing He, Xingyang Zhang*, Youyuan Sun, Yan Zeng and Huan Dai \\ Wuhan Institute of Design and Sciences, Wuhan 430205, China
}

\begin{abstract}
The purpose of this study is to explore the landscape quality of aquatic plants in the landscape water in Wuhan, reveal the rules of its construction, and provide some basis for landscape design and evaluation of aquatic plants. Based on the six representative parks in Wuhan, 9 quantitative and qualitative indexes were selected, and the evaluation model was constructed by using the analytic hierarchy process(AHP). The results showed that a total of 36 species of aquatic plants were found, mainly emergent plants. The five research objects are in grade I and II, and only the aquatic plants in Shahu Park are at the level of level III, which indicates that the quality of aquatic plants in the main landscape water of Wuhan is at an excellent level. The evaluation model can objectively be used in the Wuhan landscape water body . Based on the evaluation results, 3 excellent aquatic plant plots are recommended.
\end{abstract}

\section{Preface}

Artificial water landscape is an important part of urban landscape. With the development of cities, how to use aquatic plants to create urban water landscape is a hot topic in academic circles at home and abroad [1]. In the evaluation research of plant landscape, it is mainly aimed at the evaluation of terrestrial plant landscape [23]. Aquatic plants are more concerned with the study of diversity. At present, no special method has been established for the evaluation of aquatic plant landscape [4]. In particular, the use of multidisciplinary methods to quantitatively evaluate the species richness of aquatic plant landscapes has rarely involved [5].

Known as "the city of a thousand lakes", Wuhan is rich in water resources and diverse in water body forms, but there are problems such as insufficient application types and scope of aquatic plants and monotonous configuration [6]. In order to understand the status quo and configuration of aquatic plants in Wuhan water landscape, this study focused on 6 artificial landscape waters in Wuhan.The application status of aquatic plants was investigated, and the landscape quality of aquatic plants was comprehensively analyzed from quantitative and qualitative perspectives by using analytic hierarchy process (AHP). In order to provide a theoretical basis for the effective utilization and optimal allocation of aquatic plants in the water body of urban landscape, the model of plant allocation suitable for urban landscape water body was studied.

\section{Overview and methods of research}

\subsection{Research Site Overview}

The study area is located in Wuhan, Hubei Province, ranging from $113^{\circ} 41^{\prime} \sim 115^{\circ} 05^{\prime} \mathrm{E}$ and $29^{\circ} 58^{\prime} \sim 31^{\circ} 22^{\prime} \mathrm{N}$, which belongs to subtropical monsoon climate. According to the distribution of aquatic plants in Wuhan, six typical water landscapes were selected as the research objects, including Jiefang Park, Jinyinhu Wetland Park, Wuhan Botanical Garden, Shahu Park, Yuehu Park and Canglongdao Wetland Park.

\subsection{The research methods}

\subsubsection{Survey method}

Aquatic plants is wet marshes or the shore zone in water plants, according to plant ecological habits can be divided into four categories: emergent plants, floating leaf plants, floating plants, submerged plants[7-8]. According to the water area and the distribution of aquatic plants in each park in Wuhan, the plots were set up. According to the water area, 35 plots were selected from Wuhan botanical garden, 30 plots from Jinyinhu Wetland Park, 20 plots from Jiefang Park, and 15 plots from each of the other three parks. The size of each plot was $50 \mathrm{~cm} \times 50 \mathrm{~cm}$ [9]. Representative plots were selected from the water bodies of each park. To ensure the randomness of plots and the authenticity of data, that plots were selected without consciously choosing the plots of good or bad aquatic plant landscape communities.

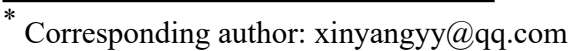


The aquatic plant communities were examined in spring (April), summer (June) and autumn (October). The author took photos on site and record the name, quantity, health condition, living habits and seasonal phase of aquatic plants in each plot. The Simpson Diversity Index calculates the diversity of aquatic plants, which are formula (1) and formula (2).

$$
\begin{aligned}
& \mathrm{D}=1-\sum \mathrm{P}_{\mathrm{i}}{ }^{2} \\
& \mathrm{Pi}=\mathrm{Ni} / \mathrm{N}
\end{aligned}
$$

In the formula, $\mathrm{Ni}$ is the number of individuals in the $\mathrm{i}$ species, and $\mathrm{N}$ is the total number of individuals in all species.

The diversity index of aquatic plants was selected from the summer survey data, because most aquatic plants thrive in summer and have a wide range of plant life types, which are more representative [10]. To some extent, the overall landscape quality of the park is related to the landscape quality of the aquatic plant community in the park, so landscape evaluation is very important for the landscape quality.The Simpson diversity index was calculated based on the classification criteria of emergent plants, floating leaf plants, floating plants, submerged plants. The viewing characteristics are based on flower viewing, fruit viewing, leaf viewing, or other 4 viewing types, and the Simpson diversity and viewing season Simpson diversity are calculated.

\subsubsection{Establishment of evaluation model}

The selection of evaluation factors directly affects the accuracy of the evaluation system. The evaluation system must be able to take into account the multiple levels and overall properties of the target. According to the nature and basic situation of aquatic plants, and based on the previous research results [11-12], after seeking the opinions of many experts, an evaluation model was established (Table 1).

Table 1. Landscape water aquatic plant landscape evaluation system

\begin{tabular}{ccc}
\hline $\begin{array}{c}\text { Target } \\
\text { layer(A) }\end{array}$ & $\begin{array}{c}\text { Criterion } \\
\text { layer (B) }\end{array}$ & Indicator layer (C) \\
\hline $\begin{array}{c}\text { Evaluation } \\
\text { of aquatic } \\
\begin{array}{c}\text { Plants } \\
\text { in } \\
\text { landscape } \\
\text { waters }\end{array}\end{array}$ & $\begin{array}{c}\text { Plant } \\
\text { diversity B1 }\end{array}$ & $\begin{array}{c}\text { Species diversity index C1 } \\
\text { Life forms diversity C2 } \\
\text { Diversity of ornamental } \\
\text { characteristics C3 }\end{array}$ \\
\cline { 2 - 3 } & $\begin{array}{c}\text { Plant } \\
\text { landscape } \\
\text { coordination } \\
\text { B2 }\end{array}$ & $\begin{array}{c}\text { Plant health status C5 } \\
\text { Coordination of plants and } \\
\text { habitats C6 }\end{array}$ \\
& $\begin{array}{c}\text { Coordination between plants and } \\
\text { the overall environment C7 }\end{array}$ \\
\cline { 2 - 3 } & $\begin{array}{c}\text { Plant } \\
\text { landscape } \\
\text { service B3 }\end{array}$ & $\begin{array}{c}\text { Plant landscape accessibility C8 } \\
\text { Habitability of plant landscape } \\
\text { C9 }\end{array}$ \\
\hline
\end{tabular}

Data processing uses two methods. For quantitative indicators, the results were calculated by formula (1) and (2). The evaluation of qualitative indicators involves certain professional knowledge, so 10 teachers, 10 graduate students and 40 undergraduates of landscape architecture are invited to engage in teaching. Through the way of slide show, landscape ecology and landscape aesthetics as the basis of judgment, the target objects were rated.Each qualitative evaluation factor was divided into four grades, and the scores were rated on 10 -point scale, including first $\operatorname{grade}(8<\mathrm{a} \leq 10)$, second grade $(6<\mathrm{b} \leq 8)$, third grade $(4<\mathrm{c} \leq 6)$, and fourth grade $(d \leq 4)$.

\subsubsection{Evaluation index weight determination}

When the weight was determined, 1-9 ratio scale method was used to construct a judgment matrix, and the weight and consistency check calculation was performed with reference to the method of Xushubai [13]. After calculation, the relative weight of each item and factor to the criterion was obtained from the judgment matrix, and the consistency, reliability and accuracy of the judgment matrix was checked. In the calculation, $C R$ value (random consistency ratio) should be guaranteed to be less than 0.1 , and then the total hierarchical sorting and consistency test should be carried out to obtain the weight of matrix indexes of each layer (Table 2).

Table 2. Total weight of aquatic plant evaluation factors in

\begin{tabular}{ccccc}
\hline $\begin{array}{c}\text { Target } \\
\text { layer }\end{array}$ & $\begin{array}{c}\text { Criterion } \\
\text { layer }\end{array}$ & $\begin{array}{c}\text { weighted } \\
\text { value }\end{array}$ & $\begin{array}{c}\text { index } \\
\text { layer }\end{array}$ & $\begin{array}{c}\text { Total } \\
\text { sequencing } \\
\text { weight }\end{array}$ \\
\hline & $\mathrm{B} 1$ & 0.516 & $\mathrm{C} 1$ & 0.311 \\
Evaluation & & & $\mathrm{C} 2$ & 0.092 \\
$\begin{array}{c}\text { of aquatic } \\
\text { plants in }\end{array}$ & $\mathrm{B} 2$ & \multirow{2}{*}{0.210} & $\mathrm{C} 3$ & 0.069 \\
landscape & & & $\mathrm{C} 4$ & 0.044 \\
waters & & & $\mathrm{C} 6$ & 0.102 \\
& $\mathrm{~B} 3$ & 0.274 & $\mathrm{C} 7$ & 0.050 \\
& & & $\mathrm{C} 9$ & 0.058 \\
\end{tabular}

\section{Results and analysis}

\subsection{Species and distribution of aquatic plants}

In the survey, a total of 36 aquatic plants, 26 emergent plants, 2 floating plants, 2 floating leaf plants and 6 submerged plants were found. Wuhan Botanical Garden has the most abundant species of aquatic plants, including 24 species. Followed by Jiefang Park and Jingyinghu Wetland Park, both 17. There are 14 species in Shahu Park and 13 aquatic plants in Yuehu Park. Jinyinhu Wetland Park has a dense distribution of aquatic plants and abundant plant species. The aquatic plants in Yuehu park and Shahu park are mostly emergent plants and less submerged plantsYuehu park, Shahu park for more emergent plants, less submerged plants (Table 3). A is Jiefang Park; B is Jinyinhu Wetland Park; C is Yuehu Park; D is Shahu Park; E is Wuhan Botanical Garden; F is Canglongdao Wetland Park.

Table 3. Distribution of aquatic plants in Wuhan landscape water

\begin{tabular}{|l|c|c|c|c|c|c|}
\hline Floristics & A & B & C & D & E & F \\
\hline Phragmites australis & & $\sqrt{ }$ & $\sqrt{ }$ & $\sqrt{ }$ & & $\sqrt{ }$ \\
\hline Zizania latifolia & & & & $\sqrt{ }$ & & \\
\hline
\end{tabular}




\begin{tabular}{|c|c|c|c|c|c|c|}
\hline Sagittaria sagittifolia & $\sqrt{ }$ & $\sqrt{ }$ & $\sqrt{ }$ & & $\sqrt{ }$ & \\
\hline Nymphaea tetragona & $\sqrt{ }$ & $\sqrt{ }$ & & $\sqrt{ }$ & $\sqrt{ }$ & $\sqrt{ }$ \\
\hline Lythrum salicaria & $\sqrt{ }$ & $\sqrt{ }$ & & $\sqrt{ }$ & $\sqrt{ }$ & $\sqrt{ }$ \\
\hline Schoenoplectus tabernaemontani & $\sqrt{ }$ & & & & & $\sqrt{ }$ \\
\hline Thalia dealbata & $\sqrt{ }$ & $\sqrt{ }$ & $\sqrt{ }$ & & $\sqrt{ }$ & \\
\hline Myriophyllum verticillatum & $\sqrt{ }$ & $\sqrt{ }$ & & & $\sqrt{ }$ & \\
\hline Iris tectorum & $\sqrt{ }$ & $\sqrt{ }$ & $\sqrt{ }$ & $\sqrt{ }$ & $\sqrt{ }$ & \\
\hline Arundo donax & $\sqrt{ }$ & $\sqrt{ }$ & & $\sqrt{ }$ & $\sqrt{ }$ & \\
\hline Cyperus alternifolius & $\sqrt{ }$ & $\sqrt{ }$ & $\sqrt{ }$ & $\sqrt{ }$ & $\sqrt{ }$ & \\
\hline Ceratophyllum demersum & $\sqrt{ }$ & & & & $\sqrt{ }$ & \\
\hline Canna indica & & $\sqrt{ }$ & & & $\sqrt{ }$ & \\
\hline Typha orientalis & $\sqrt{ }$ & $\sqrt{ }$ & $\sqrt{ }$ & $\sqrt{ }$ & & $\sqrt{ }$ \\
\hline Trapa incisa & & & $\sqrt{ }$ & & & \\
\hline Lemna minor & $\sqrt{ }$ & & & $\sqrt{ }$ & $\sqrt{ }$ & \\
\hline Alternanthera philoxeroides & $\sqrt{ }$ & $\sqrt{ }$ & $\sqrt{ }$ & & $\sqrt{ }$ & $\sqrt{ }$ \\
\hline Hydrilla verticillata & & & & & $\sqrt{ }$ & \\
\hline Nelumbo nucifera & & $\sqrt{ }$ & & $\sqrt{ }$ & $\sqrt{ }$ & \\
\hline Potamogeton crispus & $\sqrt{ }$ & $\sqrt{ }$ & $\sqrt{ }$ & $\sqrt{ }$ & & \\
\hline Nuphar pumilum & & & & $\sqrt{ }$ & $\sqrt{ }$ & \\
\hline Pontederia cordata & & & & & $\sqrt{ }$ & \\
\hline Iris pseudacorus & & & & & $\sqrt{ }$ & \\
\hline Cabomba caroliniana & & & & & $\sqrt{ }$ & \\
\hline Spirodela polyrrhiza & $\sqrt{ }$ & $\sqrt{ }$ & $\sqrt{ }$ & & $\sqrt{ }$ & $\sqrt{ }$ \\
\hline Lolium perenne & $\sqrt{ }$ & & & & & \\
\hline Sparganium stoloniferum & $\sqrt{ }$ & & & & & \\
\hline Caldesia parnassifolia & & $\sqrt{ }$ & & & & \\
\hline Phyllostachys heteroclada & & $\sqrt{ }$ & $\sqrt{ }$ & & $\sqrt{ }$ & $\sqrt{ }$ \\
\hline Nymphoides peltata & & & $\sqrt{ }$ & $\sqrt{ }$ & & \\
\hline Eichhornia crassipes & & & $\sqrt{ }$ & & & \\
\hline Monochoria korsakowii & & & & $\sqrt{ }$ & $\sqrt{ }$ & \\
\hline Potamogeton distinctus & & & & & $\sqrt{ }$ & \\
\hline Vallisneria natans & & & & & $\sqrt{ }$ & \\
\hline Cortaderia selloana & & & & & $\sqrt{ }$ & \\
\hline Sium suave & & & & & & $\sqrt{ }$ \\
\hline
\end{tabular}

\subsection{Landscape evaluation results}

According to the park green space landscape quality index, the landscape water body aquatic plant landscape in Wuhan is divided into 4 levels [14]. That is, level I indicates that the landscape quality is very good, level II indicates that the landscape quality is good, level III indicates that the landscape quality is average, and level IV indicates that the landscape quality is poor (Table 4) . Based on the score of the comprehensive evaluation, the ranking and ranking of each park were obtained (Table 5). Among them, the quality of aquatic plant landscape in Jinyinhu Wetland Park is Grade I ; the quality of aquatic plant landscape in Jiefang Park, Wuhan Botanical Garden, Yuehu Park, and Canglongdao Wetland Park is Grade II; Shahu Park is Grade III, and there is no Grade IV(Table 6). Most of them are in grade I and grade II, which indicates that the allocation of aquatic plants in landscape water bodies in Wuhan is at an excellent level.
Table 4. Landscape quality grading table

\begin{tabular}{|c|c|c|c|c|}
\hline $\mathrm{M}(\%)$ & $100-80$ & $80-60$ & $60-40$ & $<40$ \\
\hline $\begin{array}{c}\text { Landscape } \\
\text { quality grade }\end{array}$ & I & II & III & IV \\
\hline $\begin{array}{c}\text { Standard of } \\
\text { evaluation }\end{array}$ & $\begin{array}{c}\text { Beyond } \\
\text { compare }\end{array}$ & Preferably & General & Poor \\
\hline
\end{tabular}

Table 5. Evaluation index of urban landscape aquatic plants in

\begin{tabular}{|l|c|c|c|c|c|c|}
\hline Index & $\mathrm{A}$ & $\mathrm{B}$ & $\mathrm{C}$ & $\mathrm{D}$ & $\mathrm{E}$ & $\mathrm{F}$ \\
\hline C1 & 0.79 & 0.81 & 0.74 & 0.53 & 0.83 & 0.64 \\
\hline C2 & 0.74 & 0.78 & 0.79 & 0.63 & 0.83 & 0.67 \\
\hline C3 & 0.73 & 0.79 & 0.76 & 0.62 & 0.79 & 0.77 \\
\hline C4 & 0.78 & 0.81 & 0.77 & 0.65 & 0.79 & 0.66 \\
\hline C5 & 7.42 & 7.80 & 6.15 & 5.02 & 6.76 & 7.44 \\
\hline C6 & 7.42 & 8.50 & 6.17 & 6.24 & 8.53 & 7.77 \\
\hline C7 & 7.11 & 8.64 & 6.11 & 6.07 & 8.45 & 8.51 \\
\hline C8 & 7.81 & 7.49 & 6.28 & 6.59 & 6.43 & 5.86 \\
\hline C9 & 7.16 & 8.43 & 6.89 & 6.39 & 8.46 & 8.06 \\
\hline
\end{tabular}

Table6. Comprehensive evaluation of scoring and sorting tables

\begin{tabular}{|c|c|c|c|c|}
\hline Park & $\begin{array}{c}\text { Integrated } \\
\text { assessment } \\
\text { value }\end{array}$ & $\begin{array}{c}\text { Comprehensive } \\
\text { evaluation } \\
\text { index }\end{array}$ & Sort & Grade \\
\hline A & 7.57 & $75.7 \%$ & 3 & II \\
\hline B & 8.05 & $80.5 \%$ & 1 & I \\
\hline C & 6.99 & $69.9 \%$ & 5 & II \\
\hline D & 5.90 & $59.0 \%$ & 6 & III \\
\hline E & 7.88 & $78.8 \%$ & 2 & II \\
\hline F & 7.00 & $70.0 \%$ & 4 & II \\
\hline
\end{tabular}

A: Jiefang Park; B: Jinyinhu Wetland Park; C: Yuehu Park; D: Shahu Park ; E: Wuhan Botanical Garden; F: Canglongdao Wetland Park.

Based on the evaluation results, representative samples of aquatic plants in the three parks with higher scores were recommended. Sample square 1 is a typical sample square in Jinyinhu Wetland Park: Thalia dealbata + Myriophyllum verticillatum + Nymphaea tetragona + Nelumbo nucifera + Sagittaria sagittifolia . This quadrat takes into account the emergent plants, floating plants and submerged plants. This community is rich in plant hierarchy, with flowers in two seasons and leaves in four seasons. The second sample is a typical sample in Wuhan Botanical Garden: Potamogeton distinctus + Pontederia Cordata + Iris tectorum + Alternanthera philoxeroides + Ceratophyllum demersum. The quadrat has high species diversity, rich landscape color, and different landscapes in each season. The third sample was selected from typical plant communities in Jiefang Park: Iris pseudacorus + Thalia dealbata + Monochoria korsakowii + Nuphar pumilum + Lythrum + Lolium perenne. The plot is dominated by emergent plants with a long flowering period.

\section{Conclusion and discussion}

The scientization and quantification of aquatic plant landscape is the focus and difficulty of garden scientific research, which is of great significance for guiding the planning and design work [15].The park landscape evaluation system established by the author has quantitative indicators and qualitative indicators. The 
results show that the highest weight value is plant diversity, which is 0.516 . The second is plant landscape coordination and plant landscape service, respectively 0.274 and 0.21 . It indicates that people pay more and more attention to the richness of plant landscape and the ornamental value of landscape. Among the aquatic plants in the sample, most of emergent aquatic plants in the sample is Sagittaria sagittifolia, Monochoria korsakowii, Lythrum salicaria, Thalia dealbata, Iris pseudacorus. The floating leaf plant Nymphaea tetragona is the most common. Submerged plants are mainly Cabomba caroliniana, Ceratophyllum demersum, Vallisneria natans, etc. Most of the aquatic plants grown in landscape water bodies are common local species. These aquatic plants not only adapt to the native growing environment, but also have basic ornamental value and environmental adaptability. The water in Jinyinhu Wetland Park belongs to the natural water body, with less human disturbance. The diversity of ornamental characteristics and seasonal diversity of plants in the park is relatively high, and the aquatic plant landscape is coordinated with the surrounding environment. According to the shape of the pool and the depth of the water, aquatic plants of different life forms are planted in different areas of Wuhan Botanical Garden. The height, crown width, seasonal phase, color and flowering period of aquatic plants are different, which constitute a unique water landscape. The aquatic plants in the garden are well equipped, most of which are natural landscape patterns. However, due to the limited water area and stagnant water, the ornamental diversity of aquatic plants in the park is low. Yuehu Park and Shahu Park have a large water surface area, and the surrounding water bodies are mostly hard banks. The distribution of aquatic plants in the garden is scattered and not compact enough. There are only plant species distributed in blocks in specific areas, and lack of artificial maintenance.

According to the size, width, water quality and other environmental conditions of the water surface, the landscape configuration of aquatic plants needs to combine the local aquatic plants with the living type, ornamental type and seasonal phase to form a rich and beautiful aquatic plant community. Landscape water in the park needs to further improve the plant configuration, staggered planting, avoid the viewing gap period, to achieve the four seasons can be enjoyed.

The multi-factor evaluation method avoids the dominant effect of a single factor on the evaluation results. In different seasons, the visual effects of the landscape often change to some extent. Taking into account the impact of seasonal changes on the score, the author sampled the plots in spring, summer, and autumn, increasing the scientificness of the experiment [16].

There are some shortcomings in this study, only 60 professionals were invited. In fact, the more people are invited to evaluate, the more samples are obtained, and the the results will be more universal. On the other hand, we need to further analyze the evaluation results of different groups of people. Only in this way can we design the questionnaire more scientifically and carry out effective evaluation, so as to obtain more reliable evaluation results [17].

\section{Acknowledgements}

This research was financially supported by the Humanities and Social Science Research Program of Hubei Provincial Education Department (16G216 、 17G119) and School-level quality course construction project (201513、2017505).

\section{References}

1. H. Tang, M. R. Ma, H. Han, etc. CJE, 32, 3, 563$570(2013)$

2. L. Zhao, Mao H.Y. NH, 7, 85-89(2013).

3. M. Liu, X. Y. Liu, L. Dong. JNFC, 29, 6, 245249(2014).

4. P. P. Ji, X. B. Gao, Y. Wang, etc. AHAS, 10, 7779(2013).

5. S. F. Weng, J. X. Zhu, Z. Y. Su, etc. FS, 1, 2026(2017).

6. X. G. Dai, T. Xiong. CLSJHU. 02, 75-80(2013).

7. S. W. Zhao, Z. B. Zhang. CCP, 2001

8. L. Wu, CFP, 2010.

9. X. H. Cui, J. K. Chen,W. Li. WHBS, 4, 17, 357-361 (1999).

10. X. Z. Xu, J. H .Xue. JNFC, 2, 27, 213-216(2012).

11. M. Sun, X. Y. Du, W. R.Yang . JBJFU, S1, 163167 ( 2010) .

12. L. Zhao, H. Y. Mao . NH, 7, 85-89 (2013):.

13. S. B. Xu, TJUP, 1998.

14. J. G.Wu, X. X. Y.. BJ: HEP, 2007.

15. H. W. Li, B. Mu, Y.Kang, etc. JHHAU, 6, 49, 828849 (2015).

16. R. X. Liu, X. Feng, L. Q. Chen. CUF, 1, 14, 18-24 (2016).

17. J. R.Lei, X. Xin, X. Q. Song, etc. JNFC, 3, 31, 262268(2016). 